\title{
A Novel Offset Feed Annular Ring Dielectric Resonator Antenna for Bandwidth Enhancement
}

\author{
K. Tulasi, K.Jyothi, B .L.V.Kumari, K. Charitha Sri, M. Mani Kavya, M. Mounika G. Divya
}

\begin{abstract}
This article presents a design and analysis of novel offset feed annular ring dielectric resonator antenna for bandwidth increment technique. The proposed antenna design consists of a square-shaped question mark feed with an annular ring. The proposed design generates triple-band characteristics by changing the feed width. The proposed design operates in the following frequency bands 2.2-2.7 GHz, 3.13-3.94 GHz \& 5.7$7.15 \mathrm{GHz}$ with corresponding bandwidth of $22 \%, 23 \%, 21 \%$. The applications of the proposed antenna are like Wi-Fi $(2.4 \mathrm{GHz})$, mobile broadband, broadband radio service ( $3.5 \mathrm{GHz})$, Radars, commercial WLAN $(6.8 \mathrm{GHz})$.
\end{abstract}

Keywords: Triple band, annular ring, Wi-Fi.

\section{INTRODUCTION}

Dielectric resonator antenna is an antenna was proposed by Professor S. A. Long in the early 1980s.Now a days DRAs are more popular among all antennas. Dielectric resonator antennas are winning antenna elements as they offer several advantages over different types of antennas[1][6].Microstrip antennas offer more conduction losses, less bandwidth, and low radiation efficiency. To overcome the above problems, DRA is another approach for the researches in present growing technology. The bandwidth of DRA depends on different parameters such as the excitation method, shape, dimensional parameters, and dielectric constant of DRA material. By introducing the air gap in the middle of the ground plane and dielectric resonator can increase the bandwidth, making a cavity-backed dielectric resonator antenna to increase gain and bandwidth [7]. For many years, several bandwidth improvement techniques have been developed for DRAs. DRAs are mainly used at microwave frequencies and higher.

Revised Manuscript Received on March 18, 2020.

* Correspondence Author

K.Tulasi*, ECE department, Bapatla Women's Engineering College, Acharya Nagarjuna University, Andhra Pradesh, India.Email: tulasiy078@gmail.com.

K.Jyothi, ECE department, Bapatla Women's Engineering College, Acharya Nagarjuna University, Andhra Pradesh, India.Email: jyothikonatham1999@gmail.com.

B.L.V Kumari, ECE department, Bapatla Women's Engineering College, Acharya Nagarjuna University, Andhra Pradesh, India.Email: : bollaveerakumari13@gmail.com

K.Charithasri, ECE department, Bapatla Women's Engineering College, Acharya Nagarjuna University, Andhra Pradesh, India. Email: koyyanacharithasri@gmail.com.

M.Mani kavya, ECE department, Bapatla Women's Engineering College, Acharya Nagarjuna University, Andhra Pradesh, India.Email: mmanikavya@gmail.com.

M.Mounila, ECE department, Bapatla Women's Engineering College, Acharya Nagarjuna University, Andhra Pradesh, India.Email: mounimandragutti@gmail.com.

G.DIVYA,M.Tech,(Ph.D), Assistant Professor, Dept of ECE.

(C) The Authors. Published by Blue Eyes Intelligence Engineering and Sciences Publication (BEIESP). This is an open access article under the CC BY-NC-ND license (http://creativecommons.org/licenses/by-nc-nd/4.0/)
One of the best methods for improving the bandwidth of cylindrical DRA is to detach a segment of the central chunk of the DRA to form halo or annular i.e. annular ring DRA.An annular ring-shaped DRA is another type of DRA. This antenna offers more bandwidth, low $Q$ factor, fabrication is easy. The Annular ring DRA offers a firm configuration which does not use the parasitic elements to enhance the bandwidth [8-9]. In this design, the bandwidth is very less by taking the cylindrical DRA or rectangular DRA about (15\%). So this annular ring DRA with the height of $(8 \mathrm{~mm})$ is used for bandwidth enhancement. The material used for the substrate of the proposed antenna is FR4 . By introducing a circular patch along with the feed and adjusting the height of the annular ring, the bandwidth is increased. The article is orderd in the following manner :Antenna geometry, Antenna explanation, Results, Conclusion.

\section{ANTENNA GEOMETRY}

The feeding structure and proposed antenna are shown in Figs.1a and 1.b respectively. The proposed antenna is designed on an FR4 substrate $(\varepsilon r=4.4)$. The annular ring DRA, alumina $\left(\varepsilon_{\mathrm{r}}=9.9\right)$. By optimizing the dimensions of the feed $(2.5 \mathrm{~mm})$ for best impedance matching $(53.1 \Omega)$. The vertical strip is used to improve the gain. The dimensions of the proposed antenna are given in Table1.

\section{ANTENNA EXPLANATION}

By using CST microwave studio the evaluation of the proposed antenna is carried out.

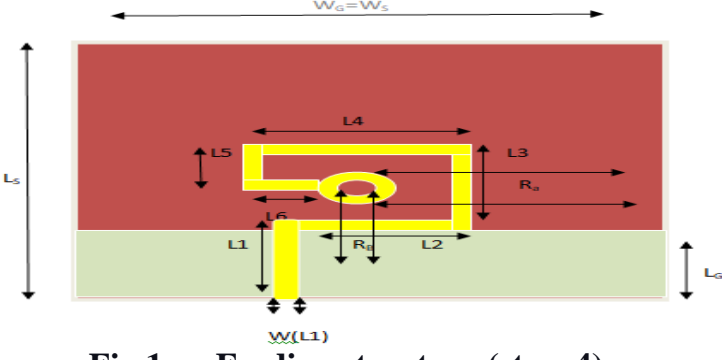

Fig.1.a . Feeding structure (stage4)

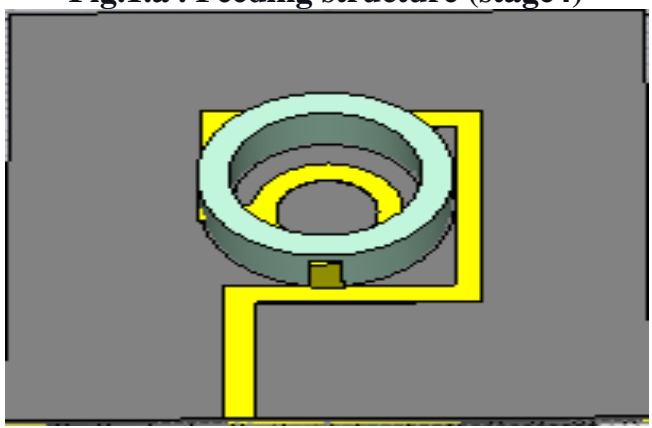

Fig.1.b. Top view of the proposed antenna

Published By:

Blue Eyes Intelligence Engineering DOI: 10.35940/ijeat.D6834.049420

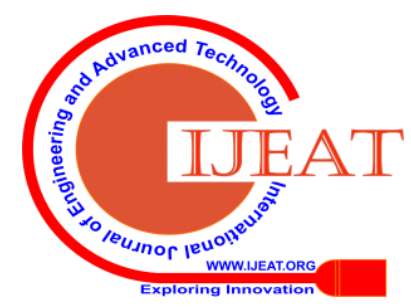


To view this article, we have separated the design of the proposed antenna into 4 different antennas. Each of the individual design is shown in Fig.2

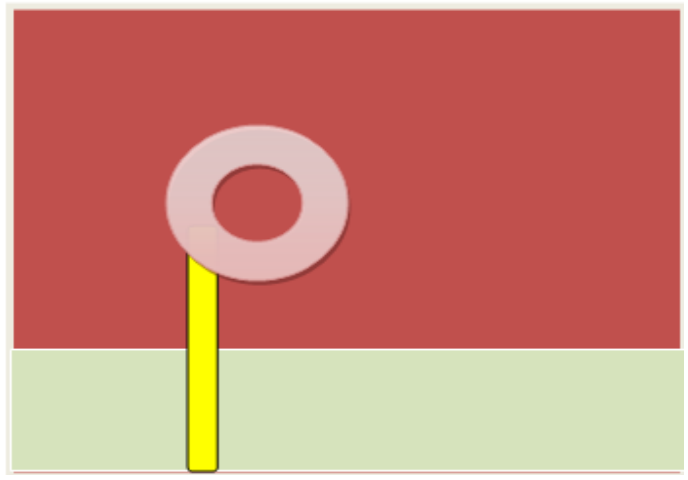

Fig.2. Stage1

Table: Dimensions

\begin{tabular}{|c|c|}
\hline Symbol & Value,mm \\
\hline $\mathrm{L}_{\mathrm{G}}$ (ground plane length) & 16 \\
\hline $\mathrm{W}_{\mathrm{G}}$ ( ground plane width) & 25 \\
\hline L $_{\mathrm{S}}$ (substrate length) & 25 \\
\hline $\mathrm{W}_{\mathrm{S}}$ (width of substrate) & 25 \\
\hline R1(outer radius) & 10 \\
\hline R2(inner radius) & 7.5 \\
\hline D(height of DRA) & 8 \\
\hline $\mathrm{H}_{\mathrm{G}}$ (ground plane height) & -0.2 \\
\hline $\mathbf{H}_{\mathrm{S}}$ (height of substrate) & 1.6 \\
\hline $\mathbf{R}_{\mathrm{a}}$ (outer radius) & 6 \\
\hline $\mathbf{R}_{\mathrm{b}}$ (inner radius) & 4 \\
\hline $\mathbf{L 1}$ & 16 \\
\hline $\mathbf{L 2}$ & 14.5 \\
\hline L3 & 21.5 \\
\hline L4 & 20 \\
\hline $\mathbf{L 5}$ & 12.5 \\
\hline L6 & 4.5 \\
\hline $\mathrm{L}_{\mathrm{S}}$ (strip length) & 6.4 \\
\hline $\mathrm{W}_{\mathrm{S}}$ (width of strip) & 2.5 \\
\hline $\mathrm{W}_{(\mathrm{L} 1)}($ width of L1) & 2.5 \\
\hline WIDTH(L2=L3=L4=L5=L6=L $)$ & 2 \\
\hline
\end{tabular}

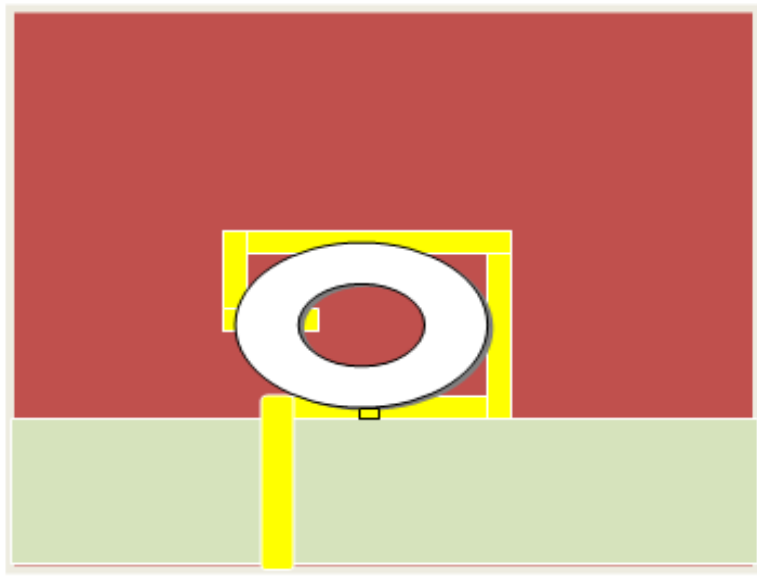

Fig.2.bStage2
Fig.2.bStage2

\section{A. Assessment of the proposed antenna structure:}

configurations is shown in Fig.3.a,3.b.

1. In stage1, only offset feed with annular ring DRA is designed. The design generates one frequency band i.e. from $5.12-7.13 \mathrm{GHz}$ with a fractional bandwidth of $34 \%$ and gain is $4.9 \mathrm{~dB}$. cases. The gain of these resonant frequencies is $3.4 \mathrm{~dB}$, $4.7 \mathrm{~dB}$. -band characteristics. DRA and a novel offset microstrip feed). The frequency ranging from $2.2-2.74 \mathrm{GHz}, 3.13-3.94 \mathrm{GHz}, 5.72$ $21 \%$. The gain of these frequencies is $2 \mathrm{~dB}, 4.80 \mathrm{~dB}$ $6.74 \mathrm{~dB}$.

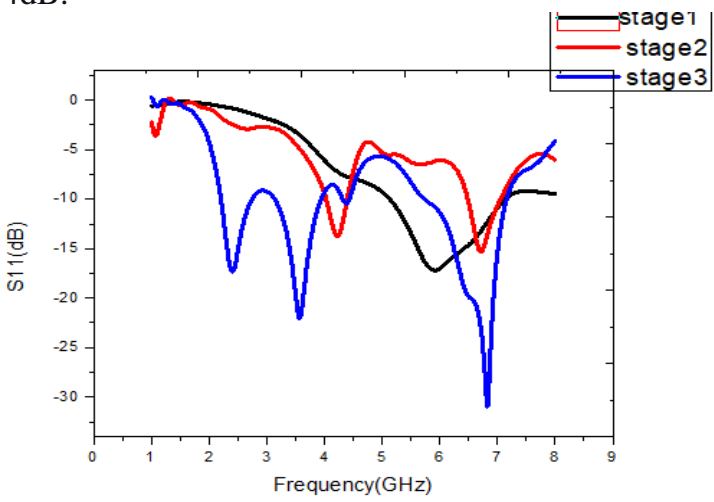
configurations.

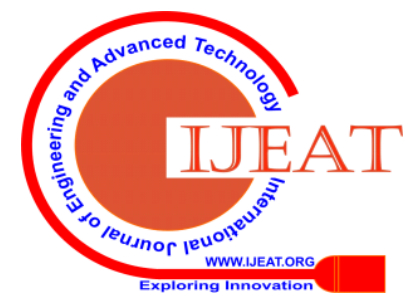


B. Excitation of TM11, HEM11 $\delta$ modes in proposed antenna and mathematical calculations:

Fig.4.a, 4.b. shows the near field distributions of antenna at $3.5 \mathrm{GHz}$ and $6.8 \mathrm{GHz}$ respectively. From Fig.4.a,4.b it is clear that $\mathrm{TM}_{11} \mathrm{HEM}_{11 \delta}$ modes are generated at $3.5 \mathrm{GHz}$ and $6.8 \mathrm{GHz}$.To find out the resonance frequency due to $\mathrm{TM}_{11}$ mode theoretically ,by using following formula

$$
f_{r}=\frac{c}{2 \pi R \operatorname{avg} \sqrt{\varepsilon_{r e}}}
$$

Where,

$$
\begin{aligned}
& R_{\text {avg }} \frac{\left(\frac{R 1}{2}\right)}{2} \quad \ldots \ldots \ldots \ldots \ldots \ldots(2) \\
& \varepsilon_{r}=\left[\frac{1}{2}\left(\varepsilon_{r \text { sub }}+1\right)+\frac{1}{2}\left(\varepsilon_{r \text { sub }}-1\right)\right]\left[1+\frac{10 h}{w}\right]^{\left(\frac{-1}{2}\right)}
\end{aligned}
$$

$\mathrm{h}=$ substrate height

$\mathrm{w}=$ width of ring.

From equations (1), (2) and (3) resonant frequency of $\mathrm{TM}_{11}$ mode is found to be $3.5 \mathrm{GHz}$.Theoretically calculated resonant frequency of $\mathrm{TM}_{11}$ mode is $4.0 \mathrm{GHz}$.

Similarly we have to calculate the resonant frequency due to $\mathrm{HEM}_{11 \delta}$ mode theoretically, by using the following formula:

$$
\begin{aligned}
& f_{r}= \\
& \frac{6.321 c}{2 \pi d \sqrt{\varepsilon_{r, e f f}+2}}\left[0.27+0.36\left(\frac{d}{2 H_{e f f}}\right)+0.02\left(\frac{d}{2 H_{e f f}}\right)^{2}\right]
\end{aligned}
$$

Where, $\varepsilon_{\text {reff }}$ is the dielectric constant of proposed antenna, $\mathrm{H}_{\text {eff }}$ is the total height of the proposed antenna, c and $\mathrm{d}(=\mathrm{R} 1 / 2)$ denote the speed of light and outer radius of annular ring DRA respectively. The value of $\varepsilon_{\text {r,eff }}$ and $H_{\text {eff }}$ can be calculated as

$$
\varepsilon_{r, \text { eff }}=\frac{H_{\text {eff }}}{\frac{H}{\varepsilon_{r, D R A}}+\frac{H_{S}}{\varepsilon_{r, s u b}}} \ldots \ldots \ldots . . .(\mathrm{b})
$$

And

$$
\mathrm{H}_{\mathrm{eff}}=\mathrm{H}+\mathrm{H}_{\mathrm{s}}
$$

From equations (a), (b) and (c) resonant frequency of $\mathrm{HEM}_{11 \delta}$ mode is $6.8 \mathrm{GHz}$. Theoretically calculated resonant frequency of $\mathrm{HEM}_{11 \delta}$ mode is $7.0 \mathrm{GHz}$.

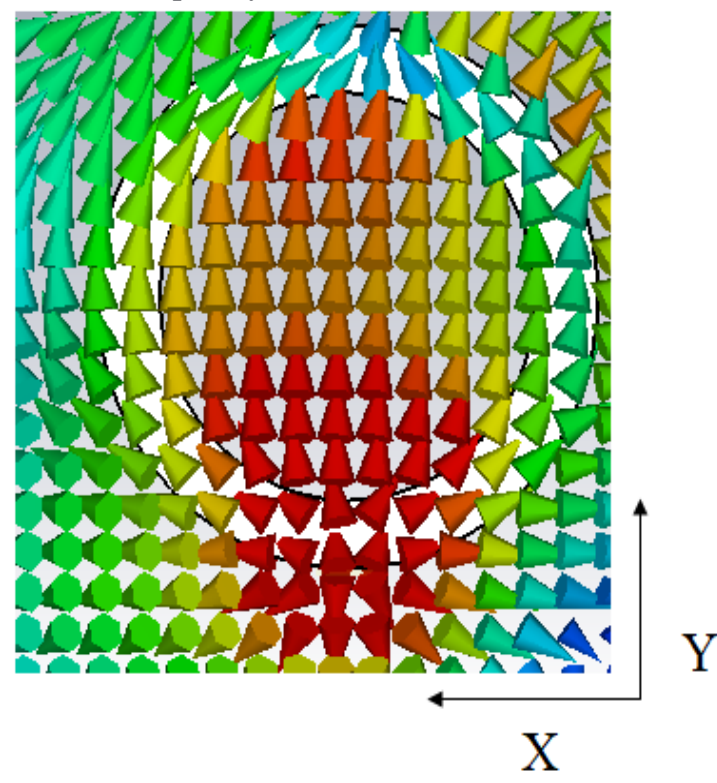

Fig.4.a E-field at 3.5GHz

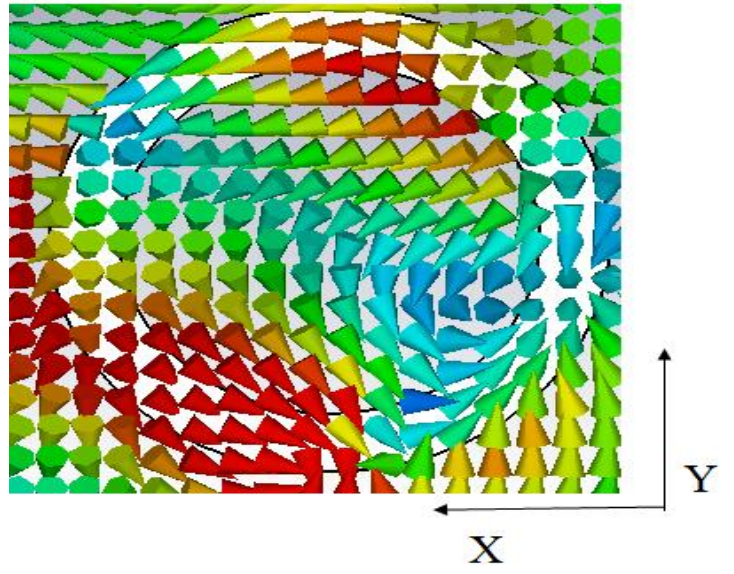

Fig.4.b E-field at 6.8GHz.

4. In this case, the overall design is

Observed without DRA (only with microstrip feed), it is operated at a lower frequency range of $2.51-3.01 \mathrm{GHz}$ with a fractional bandwidth of $18 \%$. The surface current distribution at the microstrip feed is observed at $2.73 \mathrm{GHz}$

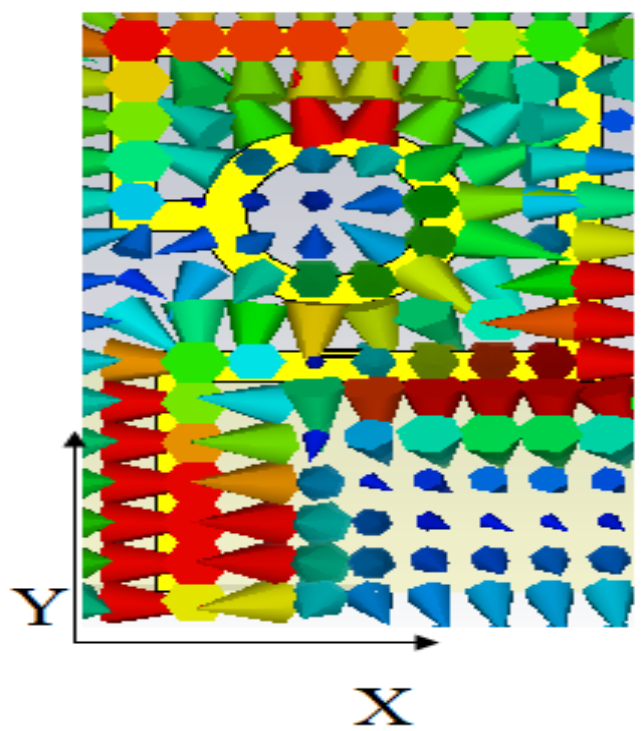

Fig.4.c. Surface current distribution at $2.73 \mathrm{GHz}$.

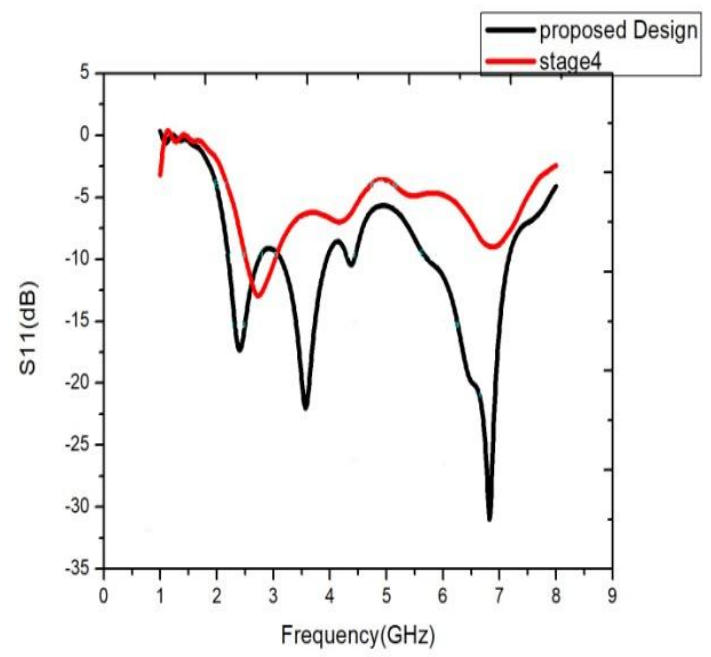

Fig.3.b .variation of S11 characteristics with and without DRA

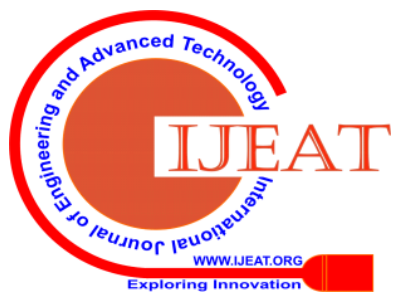


C. Comparison between different stages:

\begin{tabular}{|l|l|l|l|l|}
\hline Stage & Bandwidth & $\begin{array}{l}\text { Resonant } \\
\text { frequenc } \\
\text { y }\end{array}$ & Gain & $\begin{array}{l}\text { Directivit } \\
\mathbf{y}\end{array}$ \\
\hline $\begin{array}{l}\text { Stage } \\
1\end{array}$ & $34 \%$ & $5.91 \mathrm{GHz}$ & $4.9 \mathrm{~dB}$ & 5.07 \\
\hline Stage & $8 \%, 8 \%$ & $4.22 \mathrm{GHz}$ & $3.4 \mathrm{~dB}$ & 3.6 \\
\hline
\end{tabular}

\section{RESULTS}

Radiation is the term used to represents the emission or reception of wavefront at the antenna, specifying its strengths. Radiation pattern refers to the directional dependence of the strength of the radio waves from the antenna or another source. The field patterns are plotted as a function of electric and magnetic fields they are plotted as a logarithmic scale. Fig 5 depicts a far-field radiation pattern along the antenna E-plane and $\mathrm{H}$-plane at 2.4GHz. Fig 6 shows a far-field radiation pattern along the antenna E-plane and $\mathrm{H}$-plane at $3.5 \mathrm{GHz}$. Fig 7 shows the far field radiation pattern along the antenna E-plane and $\mathrm{H}$-plane at $6.8 \mathrm{GHz}$.

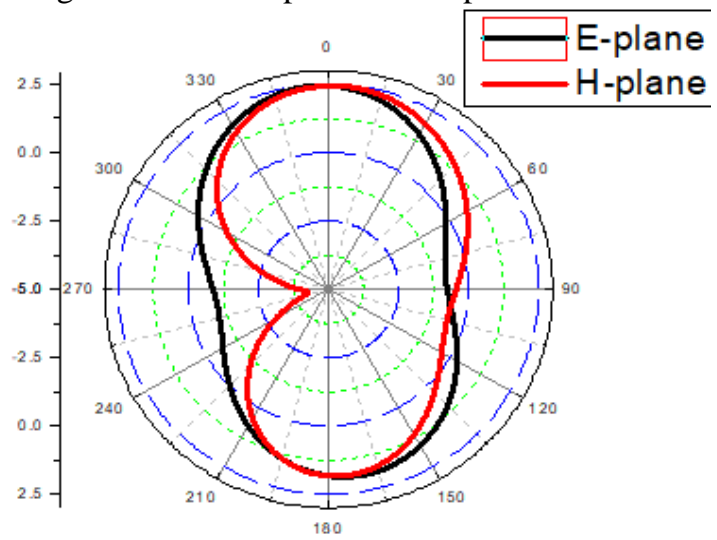

Fig .5. Radiation pattern at $2.4 \mathrm{GHz}$

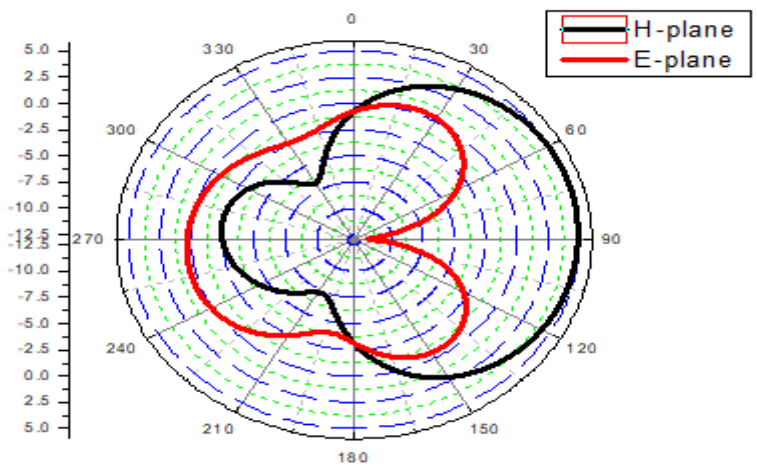

Fig. 6. Radiation pattern at 3.5GHz

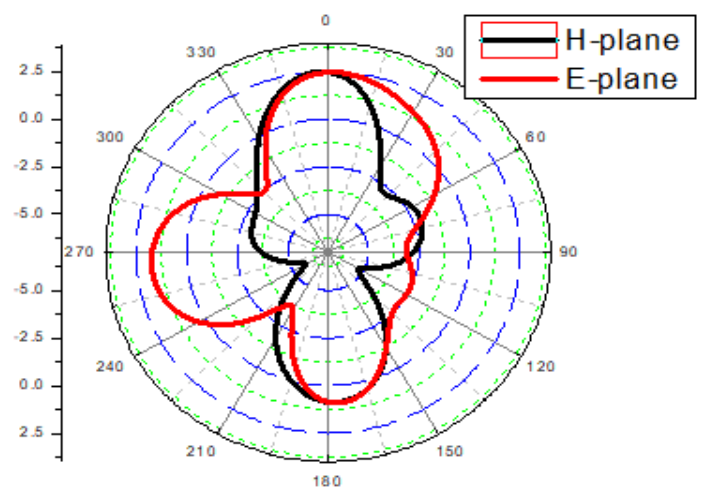

Fig. 7. Radiation pattern at $6.8 \mathrm{GHz}$.

\begin{tabular}{|l|l|l|l|l|}
\hline 2 & & $6.71 \mathrm{GHz}$ & $\begin{array}{l}6.71 \mathrm{~d} \\
\text { B }\end{array}$ & 4.9 \\
\hline Stage & $22 \%, 23 \%, 21$ & $2.4 \mathrm{GHz}$ & $2 \mathrm{~dB}$ & 2.4 \\
3 & $\%$ & $3.5 \mathrm{GHz}$ & $4.8 \mathrm{~dB}$ & 5.1 \\
& & $6.8 \mathrm{GHz}$ & $6.74 \mathrm{~d}$ & 6.9 \\
& & & $B$ & \\
\hline
\end{tabular}

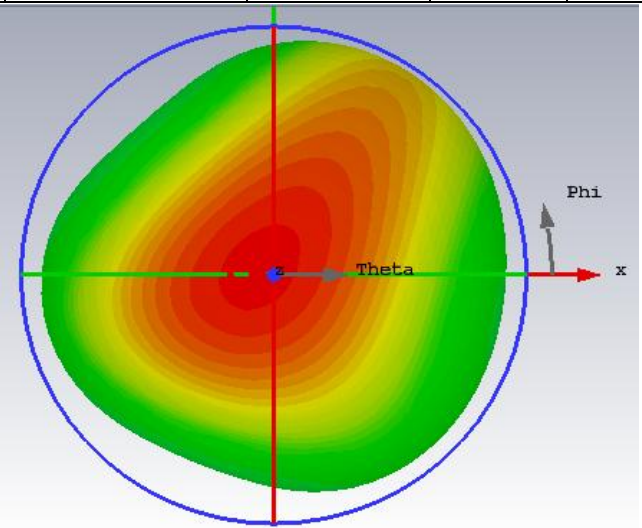

Fig .8. 3D Radiation pattern at 2.4GHz The gain and directivity of above radiation pattern is 2 dB, 2.4 respectively.

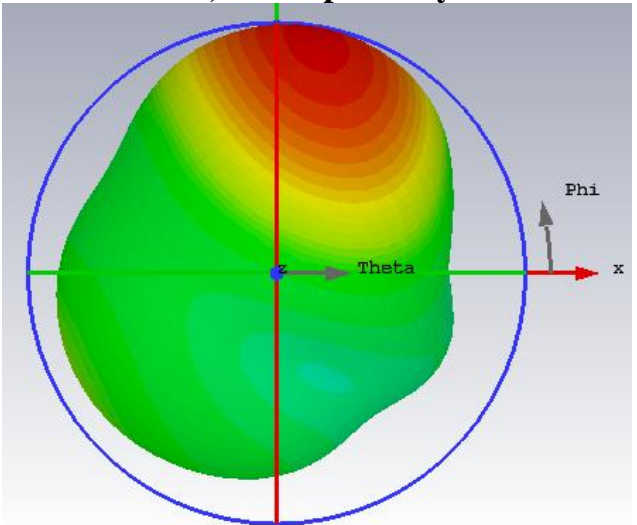

Fig. 9. 3D Radiation pattern at 3.5GHz

The gain and directivity of above radiation pattern is 4.80 $\mathrm{dB}, 5.1$ respectively.

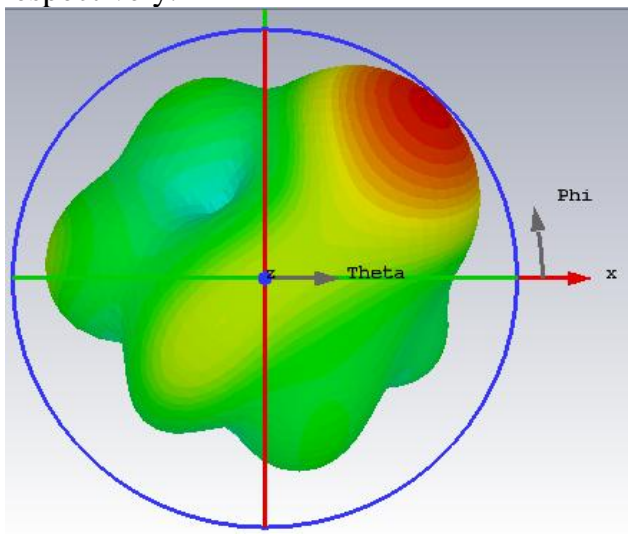

Fig. 10 . 3D Radiation pattern at $6.8 \mathrm{GHz}$

The gain and directivity of above radiation pattern is $6.74 \mathrm{~dB}, 6.9$ respectively.

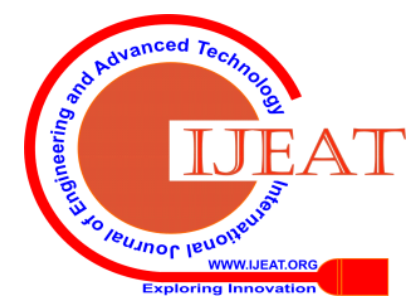




\section{CONCLUSION}

The simple implementation of offset feed with annular ring DRA has been presented. Bandwidth improvement has been achieved by using an annular ring. Here triple bands are generated with the help of feed. The proposed design generates an effective radiation pattern at 2.4 and 6.8GHz.The highest gain for the proposed design is $6.74 \mathrm{~dB}$. The proposed antenna mainly used at Wi-Fi, Radar Applications.

\section{REFERENCES}

1. Rajkishor Kumar and Raghvendra Kumar Chaudhary "A Wideband Circularly Polarized Cubic Dielectric Resonator Antenna Excited with Modified Microstrip Feed "IEEE antennas and wireless propagation letters, vol.15, 2016

2. Sudipta Maity and Bhaskar Gupta " Experimental Investigations on Wide band Triangular Dielectric Resonator Antenna"IEEE transactions on antennas and propagation ,vol.64,no.12,dec2016

3. Saeed Fakhte, Homayoon Oraizi and Ladislau Matekovits "High Gain Rectangular Dielectric Resonator Antenna Using Uniaxial Material at Fundamental Mode" IEEE transactions on antennas and Propagation, vol.65, no.1, jan2017

4. M. R. Nikkhah, J.Rashed-Mohassel and A.A.Kishk"Compact low cost phased array of Dielectric Resonator Antenna using parasitic element and capacitor loading "IEEE transactions on antennas and propagation,vol.61,no.4,pp.2318-2321,Apr2013.

5. M. K.Salem, M. A.Alkanhal and A. F. Sheta" Switched beam Dielectric Resonator Antenna Array with six reconfigurable radiation patterns" Int.J.RF Microw.Comput.AidedEng, vol.26,no.6,pp.519$530,2016$.

6. S. F. Roslan, M. R. Kamarudin, M. Khalily and M. H. Jamaluddin "An MIMO Rectangular Dielectic Resonator Antenna for 4G Applications"IEEE AntennasWirelessPropagation.Lett., vol.13, no., pp.321-324, 2014.

7. Archana Sharma, S. C. Shrivastava" Bandwidth enhancement Techniques of Dielectric Resonator Antenna" IJEST, vol.3, no.7, July2011.

8. K. M. Luk and K. W. Leung, Dielctric Resonator Antenna Textbook.

9. G.Divya,K.Jagadeesh Babu,Ramarakula Madhu,'A Novel Flower Shaped Top Loaded Transparent DRA for Isolation Improvement in MIMO System" IEEE Indian Conference on Antennas and Propagation ,pp1-4,2018.

\section{AUTHORS PROFILE}

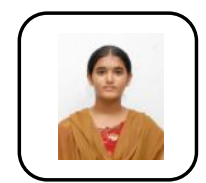

K. Tulasi is pursuing B.Tech in stream of Electronics and Communication Engineering in Bapatla Women's Engineering College, Andhra Pradesh. Her research areas include Dielectric Resonator Antenna \& Microstrip Patch Antennas.

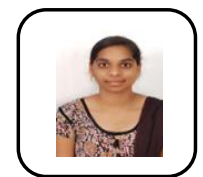

K. Jyothi is pursuing B.Tech in stream of Electronics and Communication Engineering in Bapatla Women's Engineering College, Andhra Pradesh. Her research areas include Dielectric Resonator Antenna \& Microstrip Patch Antennas.

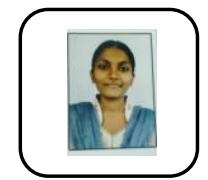

B. V. L. Kumari is pursuing B.Tech in stream of Electronics and Communication Engineering in Bapatla Women's Engineering College, Andhra Pradesh. Her research areas include Dielectric Resonator Antenna \& Microstrip Patch Antennas.

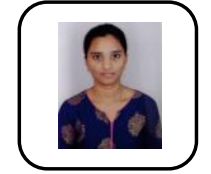

K. Charitha sri is pursuing B.Tech in stream of Electronics and Communication Engineering in Bapatla Women's Engineering College, Andhra Pradesh. Her research areas include Dielectric Resonator Antenna \& Microstrip Patch Antennas.

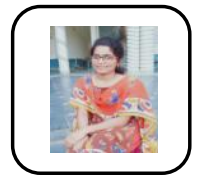

M. Mani kavya is pursuing B.Tech in stream of Electronics and Communication Engineering in Bapatla Women's Engineering College, Andhra Pradesh. Her
M. Mounika is pursuing B.Tech in stream of Electronics and Communication Engineering in Bapatla Women's Engineering College, Andhra Pradesh. Her research areas include Dielectric Resonator Antenna \& Microstrip Patch Antennas.

Divya Gudapati (Guide)is a native of Bapatla, Andhra Pradesh, India. She received her B.Tech degree in Electronics \& Communication Engineering in 2008 and M.Tech degree in Communication Systems in 2011. Department of Electronics and Communication Engineering at Bapatla Women's Engineering College. She is currently pursuing her $\mathrm{Ph} . \mathrm{D}$ degree published over 12 technical publications in various Internationa international conference in 2018. She is a student member IEEE, the world's largest technical professional organization. Her research areas include Dielectric Resonator Antennas for MIMO systems. 